\title{
Influence of subgrade defects on vibrational characteristics of ballastless track subgrade of high-speed railway
}

\author{
Qiyun WANG ${ }^{1,2, a}$, Hongbin ZENG ${ }^{2, b}$, Tingwei JIANG ${ }^{2, c}$ \\ 1 Fujian Provincial Key Laboratory of Advanced Technology and Informatization in Civil \\ Engineering(Fujian University of Technology), Fuzhou350108,china \\ 2 College of Civil Engineering, Fujian University of Technology,Fuzhou350108, china \\ awwangqiyun860519@163.com, b674811441@qq.com, '806023464@qq.com
}

Keywords: high-speed railway; subgrade defect; dynamic response; distribution law

Abstract: In order to analyze influence of subgrade defects on the dynamic characteristics of ballastless track subgrade, a three-dimensional finite element model of the CRTSII ballastless slab track subgrade was establisbed, vertical vibrational displacement and acceleration of sugrade were calculated in consideration of conventional condition and defective subgrade,such as uncompacted filling and differential settlement of sugrade, and its spacial distribution characteristics of the subgrade were discussed. It is observed that the rate of change of dynamic response amplitude of ballastless track-subgrade is less than $10 \%$ because of uncompacted filling on partial space, and the defective space will expand. The dynamic response amplitude and distribution of subgrade is obviously affected by the separation between subgrade and ballastless track for differential settlement of sugrade, thereinto vertical acceleration increases more than 2 times and create greatly negative impact on subgrade.

\section{Introduction}

At present, lots of researches are carried on vibrational characteristics of ballastless track subgrade of high-speed railway, and many achievements have been made. However, the achievements are far from the engineering practices, because the dynamic characteristics of the subgrade should be extremely complex when the train is running at high speed,and researches on dynamic response of subgrade are rarely concentrated on the effects of subgrade defects. Railway line engineering is a large project, which involves various kinds of landscapes and can hardly be filled evenly. Roadbed diseases happen from time to time because of the technology level, the construction technology, economy situation, rainfall infiltration and loaded train and many other aspects[1,2]. According to the location of railway subgrade, diseases can appear on foundation, body and bedding. According to the forms, subgrade disease can be divided into extrusion deformation, subsidence, mud and slope failure. And according to the shape of road surface, they can be divided into cutting and embankment diseases [3]. At present, many railway lines such as Shuohuang line, Jingjiu line and Jiaoji line in china have had roadbed diseases. Ballastless track has much higher requirement than ballasted track. It will cost a lot if the ballastless track subgrade has diseases. The characteristics and distribution of the dynamic acceleration, dynamic displacement of the ballastless track subgrade under high-speed train load remain to be lucubrated on condition of diseases in subgrade. 
Because of before-mentioned background, a three-dimensional dynamic finite element model of CRTSIIballastless track subgrade system was developed and validated to analyze distribution law of the vertical dynamic displacement and acceleration of the system on condition of insufficient compaction and uneven settlement in subgrade, and the influence of disease on the vibrational characteristics were studied.

\section{Ballastless track subgrade model}

Finite element model building. According to the size of subgrade of Beijing-shanghai high speed railway single line, a three-dimensional finite element model of CRTSIIballastless track subgrade system were establish by using ANSYS. The element type of rail is Beam 188 element. The element type of fastener is combin14 spring damper element. The element type of ballastless track slab, CA mortar, supporting layer and subgrade structure layers is solid45 element. Linear elastic constitutive relations was adopted for ballastless track and iscoelastic constitutive relation was adopted for subgrade. To reduce the reflection of wave on the boundary of the roadbed and receive more accurate computed results of dynamic response and save the computational cost, three dimensional viscoelastic boundary element [6] was applied in two embankment side along the direction of the line and subgrade bottom surface of 3D finite element model of ballastless track subgrade, and displacement of the two boundary that's perpendicular to the line is constrained. The equivalent stiffness of fastener is $40 \mathrm{MN} / \mathrm{m}$, and the damping coefficients of fastener is 35 $\mathrm{kN} / \mathrm{m} \cdot \mathrm{s}^{-1}$. The calculated length of finite element model is $26 \mathrm{~m}$, and the calculated depth is $9.7 \mathrm{~m}$ below the surface of the subgrade. The other calculation parameters are shown in Table 1 and Table 2.

Table 1 Geometric parameters of the finite element model

\begin{tabular}{cccc}
\hline material & height $/ \mathrm{m}$ & width $/ \mathrm{m}$ & ratio of slope \\
\hline ballastless track slab & 0.2 & 2.55 & \\
CA mortar & 0.03 & 2.55 & \\
supporting layer & 0.3 & $2.95-3.25$ & \\
\hline surface layer of subgrade & 0.4 & $6-7.2$ & \\
bottom layer of subgrade & 2.3 & $7.2-14.1$ & $1: 1.5$ \\
subgrade body & 2.0 & $14.1-21$ & \\
\hline foundation & 5 & 30 & \\
\hline
\end{tabular}

Table 2 Material parameters of finite element model

\begin{tabular}{ccccc}
\hline material & Elastic Modulus $/ \mathrm{GPa}$ & Poisson's ratio & density $/ \mathrm{kg}^{-\mathrm{m}^{-3}}$ & damping \\
\hline steel rail & 210 & 0.3 & 7830 & \\
track & 35 & 0.167 & 2500 & \\
CA mortar & 4.5 & 0.2 & 2000 & \\
supporting layer & 27 & 0.2 & 2400 & \\
surface layer of subgrade & 0.25 & 0.27 & 2250 & 0.026 \\
bottom layer of subgrade & 0.16 & 0.32 & 2130 & 0.035 \\
subgrade body & 0.12 & 0.35 & 2000 & 0.037 \\
foundation & 0.06 & 0.35 & 2000 & 0.045 \\
\hline
\end{tabular}

In this paper, the change of train dynamic load caused by complex factors like track irregularity is out of consider, then the train load can be simplified as a constant moving load. According to the distribution mode and behaviors of vehicle dynamic load and load input characteristics,a two-ca, eight-wheelset vehicle model was applied for caulation[7]. The 3D finite element model of ballastless track subgrade was established shown in Fig.1. 


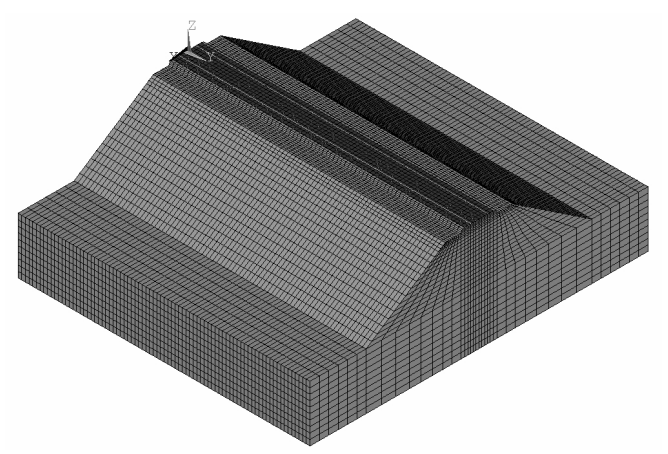

Fig.1 Finite element model of ballastless track subgrade

Disease setting .According to the common diseases in subgrade, such as insufficient compaction of filling and uneven settlement, four kinds of condition of calculation were set in the 3-D finite element model in Table 3.

Table 3 Condition of calculation for subgrade diseases

\begin{tabular}{|c|c|c|}
\hline Condition & size $/ \mathrm{m} \times \mathrm{m} \times \mathrm{m}$ & description \\
\hline 1 & $1.3 \times 1.52 \times 0.4$ & $\begin{array}{c}\text { uncompacted location in surface layer of subgrade under subgrade } \\
\text { center }\end{array}$ \\
\hline 2 & $1.3 \times 1.52 \times 0.58$ & $\begin{array}{c}\text { uncompacted location in subgrade is } 1.275 \mathrm{~m} \text { away from subgrade } \\
\text { center }\end{array}$ \\
\hline 3 & $1.3 \times 3.25$ & $\begin{array}{c}\text { the separation between supporting layer of ballastless track and } \\
\text { subgrade caused by uneven settlement }\end{array}$ \\
\hline 4 & & No diseases in subgrade \\
\hline
\end{tabular}

Condition 3 is partly void between supporting layer and subgrade caused by uneven settlement shown in Fig.2.

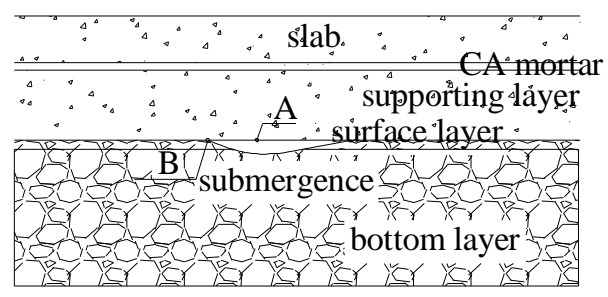

Fig.2 Sketch of submergence of subgrade 


\section{Vibrational characteristics of subgrade analysis}

Amplitude analysis. The amplitudes of vibrational characteristics of ballastless track subgrade system , listed in Table 4, are obtained by 3-D finite element model numerical calculation.

Table 4 The amplitude of dynamic response of ballastless track subgrade system

\begin{tabular}{ccccc}
\hline Dynamic response & Condition 1 & Condition 2 & Condition 3 & Condition 4 \\
\hline Rail displacement $/ \mathrm{mm}$ & 1.18 & 1.18 & 1.23 & 1.18 \\
Slab displacement $/ \mathrm{mm}$ & 0.39 & 0.39 & 0.43 & 0.39 \\
Supporting layer displacement $/ \mathrm{mm}$ & 0.39 & 0.39 & 0.43 & 0.39 \\
JCBCBM displacement $/ \mathrm{mm}$ & 0.39 & 0.39 & 0.3 & 0.39 \\
JCDCBM displacement $/ \mathrm{mm}$ & 0.36 & 0.37 & 0.3 & 0.36 \\
JCDCDM displacement $/ \mathrm{mm}$ & 0.2 & 0.21 & 0.21 & 0.21 \\
Slab acceleration $/ \mathrm{m} \cdot \mathrm{s}^{-2}$ & 13.19 & 13.08 & 17.23 & 13.08 \\
Supporting acceleration $/ \mathrm{m} \cdot \mathrm{s}^{-2}$ & 4.66 & 4.53 & 8.97 & 4.53 \\
JCBCBM acceleration $/ \mathrm{m} \cdot \mathrm{s}^{-2}$ & 2.52 & 2.45 & 0.5 & 2.44 \\
JCDCBM acceleration $/ \mathrm{m} \cdot \mathrm{s}^{-2}$ & 1.28 & 1.27 & 0.49 & 1.27 \\
JCDCDM acceleration $/ \mathrm{m} \cdot \mathrm{s}^{-2}$ & 0.21 & 0.21 & 0.22 & 0.21 \\
\hline
\end{tabular}

In the paper, JCBCBM stands for the surface of the top of the subgrade, JCBCDM stands for the surface of the bottom of the subgrade, JCDCDM stands for the surface of the base of the subgrade.

It can be shown that the amplitude difference of the dynamic response index,such as acceleration, displacement, is less than $10 \%$ on condition 1 , condition 2 and condition 4 . Results show that filling defects have limited effect on the dynamic response of track subgrade system on driving condition, because the ballastless track is big rigidity and ability to diffuse stress. However, under long-time train loads particles of filling will be more prone to redistribute and rearrange, then the condition 2 would change to the condition 3 . It is conculded that the amplitude of the dynamic responses of the track subgrade system change a lot on condition of uneven settlement of subgrade, acting as the acceleration and displacement of the track above the place with differential settlement has observably increasing. It mainly reflect in increasing dynamic acceleration and displacement of the supporting layer of track above the settlement location of subgrade, and decreasing dynamic response of subgrade below settlement location. For example, dynamic acceleration of supporting layer of track can increase $98 \%$. The amplitude of the dynamic acceleration of subgrade below the rail is $2.44 \mathrm{~m} / \mathrm{s}^{2}$, but the acceleration is only $0.56 \mathrm{~m} / \mathrm{s}^{2}$ in condition 3 . The dynamic acceleration on condition 3 is much less than normal condition 4 for that the ballastless track and the settlement of subgrade do not contact directly.

Distribution law of Acceleration. The curves between the amplitude of dynamic acceleration along depth at different position on condition 3 and condition 4 are described in Fig.3. In the figure legend, 3 stands for condition 3, 4 stands for condition 4,R stands for rail,C stands for subgrade center,S stands for supporting layer.For example, legend $\mathrm{R}(3)$ in Fig.3 stands for dynamic accelerarion of subgrade under rail on condition3. 
peak acceleration $/ \mathrm{m} / \mathrm{s}^{2}$

peak acceleration $/ \mathrm{m} / \mathrm{s}^{2}$

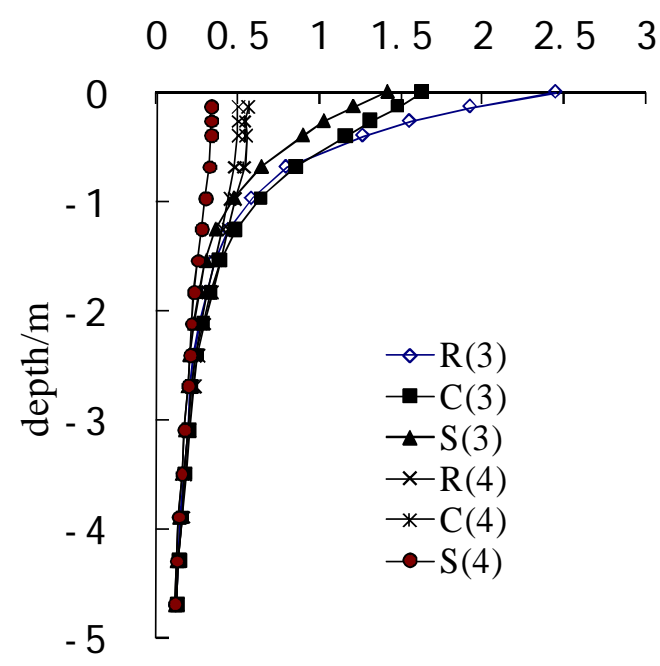

(a) Beneath point $\mathrm{A}$

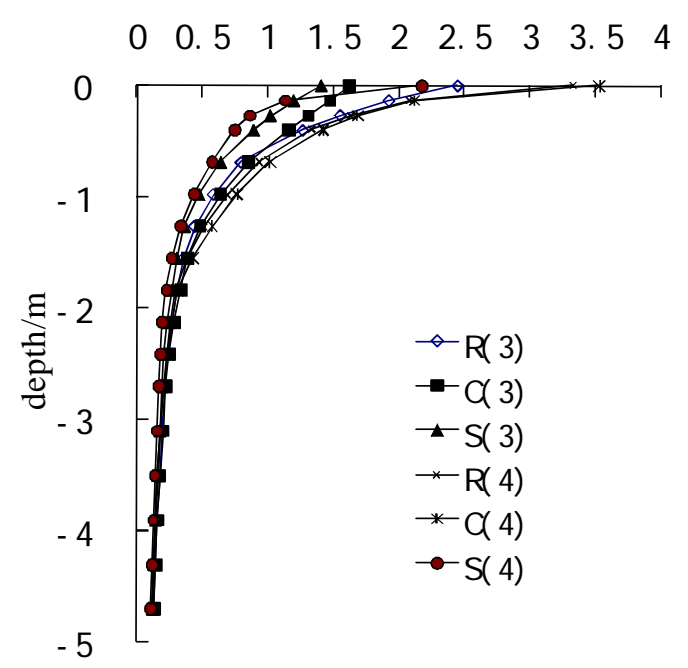

(b) Beneath point $\mathrm{B}$

Fig. 3 distribution of dynamic acceleration amplitude along depth

Fig. 3 shows acceleration of subgrade without diseases at depth 0 to $-1 \mathrm{~m}$ below the rail is more than which is below the subgrade center and the edge of the supporting layer, and the distribution law of acceleration will approach below $-1 \mathrm{~m}$ depth. The attenuation of acceleration mainly concentrated at $-1.5 \mathrm{~m}$ depth, and the attenuation rate is more than $75 \%$ on condition 4.Fig. 3 also shows that due to non direct loading, dynamic displacement of subgrade with uneven settlement below sinking central part is almost changed a little at 0 to $-1 \mathrm{~m}$ depth,and the value on condition 3 is less than that on condition 4 . The attenuation of acceleration mainly concentrated at $-1.5 \mathrm{~m}$ depth,and the attenuation rate is more than $88 \%$ on condition 4.The distribution law of acceleration along depth trend to be same on condition 3 and condition 4.

The transverse distribution curves of the dynamic acceleration amplitude are described in Fig.4.

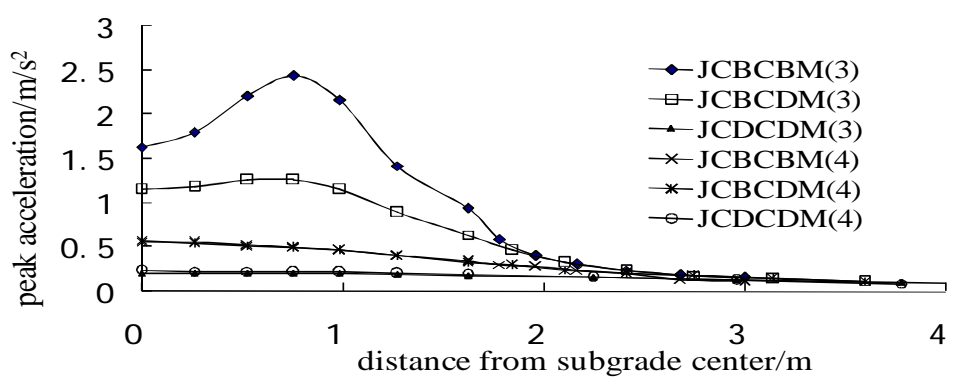

(a) cross section through point $\mathrm{A}$

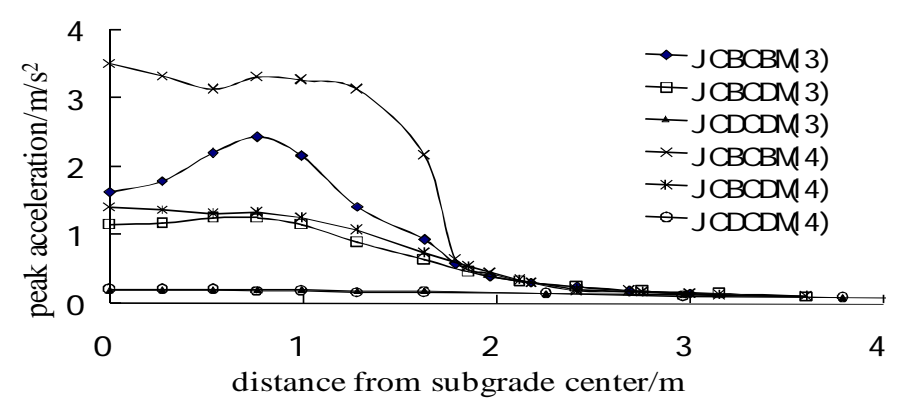

(b) cross section through point $B$

Fig.4 Transverse distribution of the dynamic acceleration amplitude 
Fig.4 shows dynamic acceleration of subgrade bed without diseases on condition 4 decreases roughly along transverse section,and the acceleration peak positions is just below the rail but the edges of the supporting layer.The acceleration of subgrade below the track is more than that outside the track, and the attenuation of acceleration in transverse is rapidly outside the track. It indicates that the vertical vibration on the surface of subgrade below the track structure is relatively heavy,and the vertical vibration is relatively slight outside the track.

The dynamic acceleration of subgrade bed in transverse section of sinking central part decreases with the increase of the distance from the subgrade center on condition 3, and the transversal law of acceleration in surface and undersuface of surface of sugbrade is similar. Fig.4 also shows the acceleration of surface of surface of sugbrade at the edge of sinking part on condition 3 is more than that on condition 4 , and decreases roughly under the track. The acceleration of the surface decreases rapidly with increase of distance from subgrade center,and the distribution law on condition 3 is trend to be similar with that on condition 4. The distribution law of acceleration in transverse section of undersuface of surface of sugbrade and undersurface of bottom of sugbrade is similar with that on condition 4.

\section{Conclusions}

The contribution of this paper is to provide dynamic responses of ballastless track subgrade subjected to high-speed train load by using 3D finite element model of ballastless track-subgrade, several findings were made:

(1) The rate of change of dynamic response, such as dynamic displacement and dynamic acceleration, which is below $10 \%$, that indicate insufficient compaction on local region have limited effect on the dynamic response of ballastless track subgrade system. However, soil particles in uncompacted filling will redistribute under the cyclic train load,then the uncompacted area will enlarge and lead to subsidence of subgrade.

(2) The affecting region of subgrade uneven settlement is mianly within $-1.5 \mathrm{~m}$ depth just below supporting layer of ballastless track, especially the surface layer of subgrade bed.It can be the reason why construction quality of subgrade should be controlled strictly, particularly the upper structural layer of subgrade.

(3) Vertical acceleration also increases more than twice that without diseases, so the filling would be destroyed and then the area of uneven settlement will persistently develop at a higher rate.

\section{Acknowledgements}

This study was partially supported by the Natural Science Foundation of Fujian under the Grants No.2015J05090 and the National Natural Science Foundation of China under the Grants No. 51508097, and also supported by the Provincial Undergraduate Training Program for Innovation and Entrepreneurship.

\section{References}

[1] Peng Hua,Zhang Hongru. Types and mechanisms of roadbed defecfs in existing railway and their detection as well as treatment[J]. Journal Engineering Geology,2005,13(2):195-199.

[2] Cheng Bohua. Formation Reasons and Treatment Measures for Railway Roadbed D iseases[J].Railway Coustruction Technology, 2011,(2): 65- 68. 
[3] Guo Xiujun,Han Yu,Meng Qingsheng,et al. Manufacture and Application of the On Board Ground Penetrating Radar for Non Invasive Inspection of Railway Subgrade Defects[J]. 2006,27(5): 139-144.

[4] Liu Zhongxin,Zhu Huili,Chen Zhenghong. Analysis of geological disasters caused by heavy rainfall along Jianghuai Section of Beijing-Kowloon Railway[J]. 2010, 31(10): 3254-3259+3264.

[5] Gu Yin,Liu Jingbo, Du Yixin. 3D consistent viscous-spring artificial boundary and viscous-spring boundary element[J]. Engineering mechanics, 2007, 24(12): 31-37.

[6] Wang Qiyun,Zhang Jiasheng,Meng Fei,et al. Study on Track-subgrade Model of High-speed Railway and Dynamical Loading[J]. Journal of the China Railway Society,2012, 34(12):90-95. 